\title{
Cartilage morphogenetic proteins: role in joint development, homoeostasis, and regeneration
}

\section{A H Reddi}

Ann Rheum Dis 2003;62(Suppl II):ii73-ii78

Background: Articular cartilage homoeostasis is critical for joint function. The steady state homoeostasis of articular cartilage is a balance between anabolic morphogens such as cartilage derived morphogenetic proteins (CDMPs) and bone morphogenetic proteins (BMPs) of the BMP family and catabolic cytokines such as interleukin (IL) 1, IL 17, and tumour necrosis factor $\alpha$. Although bone and articular cartilage are adjacent tissues, there is a profound difference in their regeneration potential. Bone has the highest potential for regeneration. On the other hand, articular cartilage is recalcitrant to repair.

Objective: To examine the hypothesis that the feeble innate regeneration ability of cartilage is due to the preponderance of catabolic cytokines such as ILI and IL17.

Results: During a systematic investigation of CDMPs and cytokines IL17B (chondroleukin) was found in bovine articular cartilage.

Discussion and conclusions: BMP-7 and IL17B are present in articular cartilage and synthesised in chondrocytes as shown by northern blots and real-time reverse transcription-polymerase chain reaction. The coexistence of anabolic morphogens and catabolic cytokines in articular cartilage has important implications for cartilage homoeostasis and regeneration. The networks of signalling systems of morphogens and cytokines determine the net capacity for regenerative morphogenesis of articular cartilage. Finally, the feeble innate capacity for articular cartilage may be improved by targeted therapy by soluble receptors to block catabolic cytokines.

$\mathrm{T}$ he morphogenesis of articular cartilage during the development and maintenance of the homoeostasis of matrix is critical for joint function. The development of the joints is intimately linked to the key steps in limb development. A limb arises from the limb bud, which consists of mesodermal cells covered by the apical ectodermal ridge. The mesodermal progenitors in the limb bud give rise to the articular cartilage and associated structures such as tendon, ligaments of the future joint. ${ }^{1}$ The joint morphogenesis occurs generally in the interzone region between the two condensations in the developing limb. The key signals are cartilage derived morphogenetic protein 1 (CDMP-1) also known as growth/ differentiation factor-5 (GDF-5) and related bone morphogenetic proteins (BMPs). The signalling by BMPs is modulated by extracellular BMP antagonists such as noggin. ${ }^{2}$ CDMP-1/ GDF-5 has several functions in joint development and morphogenesis. The absence of noggin expression in a knockout mouse caused the complete absence of joints. ${ }^{3}$ Thus, the balance between CDMP-1/GDF-5 and noggin is critical for joint morphogenesis. This article aims at providing a concise account of CDMPs and BMP signalling, including BMP antagonists such as noggin and chordin with special reference to articular cartilage development and homoeostasis.

\section{DEVELOPMENT AND STRUCTURE OF JOINT}

The development of skeleton is based on the distinct origins of appendicular and axial skeleton. The lateral plate mesoderm gives rise to the appendicular skeleton and the associated diarthrodial joints. The axial skeleton arises from the sclerotome of somites derived from paraxial mesoderm. In the human embryo the limb buds are discernible between 4 and 5 weeks, and the morphogenesis of appendicular skeletal structures, including joints, take place therein. The developmental sequence of long bones consists of a cascade that includes mesenchymal cell condensation, cartilage differentiation, and replacement of cartilage by endochondral ossification and joint morphogenesis. The phalangeal joint development is informative as multiple joints develop in the proximal-distal axis, presenting several stages of joint morphogenesis in coronal sections of the hand.

The developmental cascade of joint morphogenesis includes migration of cells, increased proliferation of condensation by cellular aggregation and followed by chondrogenesis, and is heralded by cartilage-specific type II collagen and type IX collagen. The signals for chondrogenesis include BMPs and CDMPs. In the regions of presumptive joint formation hyaluronan, hyaluronan receptors, also known as CD 44 , and hyaluronan synthase are localised. ${ }^{4}$ The increasing hyaluronan concentration results in decreased cellular adhesion, leading to cavitation in the synovium with concomitant angiogenesis and vascularisation. However, the precise molecular mechanism of joint cavitation is not clear at present. Movements associated with embryo have been implicated as critical for joint morphogenesis

The synovial membrane gives rise to the joint capsule, synovial lining, ligaments, and meniscus. The articular cartilage, unlike the growth plate cartilage is not vascularised and remains functional and expresses type II collagen and tenascin. ${ }^{5}$

The functional diarthrodial joint consists of muscle, tendons, ligaments, bone, and meniscus. The muscles generate forces for joint movement and stability. Tendons are functional connections between muscle and bone and consist of tenocytes and collagens I and III. Tendons form the myotendinous junctions. Ligaments provide a stabilising bridge between bones. The anterior cruciate and medial collateral ligaments in the knee provide stability to the joint. Any mechanical instability in the knee joint ligaments leads to

Abbreviations: $B M P$, bone morphogenetic protein; $B M P R, B M P$ receptor; $C D M P$, cartilage derived morphogenetic protein; FGF, fibroblast growth factor; GDF, growth/differentiation factor; IL, interleukin; TGF $\beta$, transforming growth factor $\beta$; TNF $\alpha$, tumour necrosis factor $\alpha$ 
Table 1 Cartilage morphogenetic proteins

\begin{tabular}{lll}
\hline Morphogen & Other names & Potential function \\
\hline $\begin{array}{c}\text { Cartilage derived morphogenetic proteins (CDMPs) } \\
\text { CDMP-1 }\end{array}$ & GDF-5 & Growth/differentiation factors (GDFs) \\
CDMP-2 & GDF-6 & Mesenchymal condensation, chondrogenesis \\
CDMP-3 & GDF-7 & Cartilage development and hypertrophy \\
Bone morphogenetic proteins & Ligament and tendon development \\
BMP-2 & BMP-2A & Cartilage and bone morphogenesis \\
BMP-4 & BMP-2B & Cartilage and bone morphogenesis \\
BMP-3 & Osteogenesis & Bone formation \\
BMP-3B & GDF-10 & Membrane bones \\
BMP-5 & - & Bone morphogensis \\
BMP-6 & - & Hypertrophy of cartilage \\
BMP-7 & Osteogenic protein 1 & Bone differentiation \\
BMP-8 & Osteogenic protein 2 & Bone formation \\
BMP-9 & - & \\
BMP-10 & - & \\
BMP-1 1 & GDF-1 1 & \\
\hline
\end{tabular}

progressive arthritis. Meniscus is a fibrocartilaginous wedgelike structure in the knee. Any damage to or loss of meniscus leads to arthritis. The central zone of adult meniscus is avascular and devoid of nerve supply; the periphery is more vascular. The great majority of collagen is type I in meniscus.

Finally, the articular cartilage in joints permits the smooth movement of the bones. The hyaline cartilage in articular cartilage is composed of type II collagen and aggrecan, a proteoglycan. The orientation of collagen fibrils conforms to the geometry of the articular cartilage surface and is generally tangential. Collagen fibrils are responsible for the tensile strength in cartilage. Over $90 \%$ of the collagen is composed of type II collagen, with the presence of minor collagens VI, IX, and XI. Proteoglycans in cartilage resist compression and are predominantly composed of the aggrecans. Decorin and fibromodulin modulate collagen II fibrillogenesis in cartilage.

\section{CARTILAGE MORPHOGENESIS}

Cartilage morphogenesis is a prerequisite for skeletal development and maintenance. The morphogenesis of cartilage determines the shape of bones and location of joints, including articular cartilage, ligaments, and tendon. CDMPs are related to BMPs and are critical for cartilage and joint morphogenesis. Cartilage morphogenesis is a multistep cascade that includes factors for initiation, promotion, and maintenance of cartilage phenotype.

Cartilage morphogenesis is a central problem during skeletal development and growth. What are the morphogenetic signals for initiation of cartilage formation and morphogenesis? The main experimental approaches for morphogen discovery are based on genetic screens, differential display, subtractive hybridisation, and expressed sequence tags in flies, frogs, and mice. This accrued information is extended to humans.

Morphogenesis of cartilage is a key rate limiting step in skeletal development. Cartilage is the blueprint for subsequent bone morphogenesis, the location of tendon and ligament insertions, and the morphogenesis of the joints. The commitment, lineage, differentiation, and morphogenesis are a developmental cascade in continuum. The morphogenesis of cartilage is a multistep process and includes initiation, promotion, maintenance, and finally, regulated cell death by apoptosis. The differentiation of a variety of cartilage such as growth plate cartilage, articular cartilage, elastic cartilage, and fibrocartilage arising from the same genetic endowment in a single subject from identical DNA is a statement of the problem and the experimental challenge. The chondrocyte has a finite lifespan in the epiphysial growth plate, whereas in articular cartilage it has a very long stable phenotype. The initial signalling morphogens and their actions are the focus of this manuscript. The biochemical and molecular approaches to cartilage morphogenesis are based on and influenced by work on BMPs, which first induce cartilage, followed by bone. Hence, all BMPs can be considered as cartilage morphogens.

\section{BONE MORPHOGENETIC PROTEINS}

It is now well known that demineralised bone matrix induced new cartilage differentiation, and the cartilage is replaced by bone by the endochondral sequence. ${ }^{67}$ The sequential cascade is reminiscent of endochondral bone development in the embryo and includes mesenchymal progenitor migration by chemotaxis, condensation, chondrogenesis, calcification, vascular invasion, bone formation, and haematopoiesis. This sequence recapitulates limb morphogenesis in the limb bud. $^{89}$

The bioactive morphogens in the demineralised extracellular bone matrix have been dissociatively extracted and purified..$^{10-13}$ A family of BMPs was identified, isolated, and cloned. There are three distinct subfamilies, including BMP-2 and BMP-4; BMP-3 and BMP-3B; BMPs 5, 6, 7, and 8 (table 1). The BMPs are members of the transforming growth factor $\beta$ (TGF $\beta$ ) superfamily. The TGF $\beta$ superfamily includes activins, inhibins, müllerian duct inhibitory substance, nodal, ${ }^{14}$ glial derived neurotrophic factor, and GDFs. ${ }^{13}$ The BMP superfamily members are synthesised as larger precursors with hydrophobic signal sequence, a conserved carboxy terminal domain with canonical 7-cysteines, of which one cysteine is involved in an intermolecular disulphide linkage for each dimer. There are three intramolecular disulphide bonds in each monomer. The dimeric confirmation is critical for biological function.

\section{CARTILAGE DERIVED MORPHOGENETIC PROTEINS}

The isolation and cloning of a family of BMPs (table 1) from bone prompted us to search for cartilage morphogenetic proteins from articular cartilage. A systematic study examined the presence of chondrogenic proteins from bovine cartilage. Bovine articular cartilage slices were extracted in buffered $1.2 \mathrm{M}$ guanidine hydrochloride. The extract was exchanged with $6.0 \mathrm{M}$ urea in $0.05 \mathrm{M}$ Tris- $\mathrm{HCl}, \mathrm{pH} 7.4$ and further purified by heparin affinity chromatography and preparative gel electrophoresis. An active cartilage morphogenetic protein activity was identified based on a reconstitution with insoluble collagenous matrix. A simultaneous complementary approach using reverse transcription-polymerase chain reaction was used. Degenerate oligonucleotide primers were used 
to look for BMP-like molecules. Two new CDMPs, CDMP-1 and CDMP-2, were cloned. The bovine CDMP-1 sequence was used to get a full length human CDMP-1. A $3 \mathrm{~kb}$ transcript of CDMP-1 was expressed in articular cartilage. ${ }^{16}$ The CDMP-2 was found in articular cartilage, skeletal muscle, and placenta. It is of interest, that in situ hybridisation using CDMP-1 antisense RNA, sites of mesenchymal condensation, were intensely positive for CDMP-1 expression. CDMP-2 was localised in the hypertrophic chondrocytes of the epiphysial growth plate. The elegant work of Storm and colleagues identified ${ }^{17}$ expression of GDF-5, also called CDMP-1. Mutation in the GDF-5 (CDMP-1) gene results in brachypodism in mice.

CDMP-1 (GDF-5) stimulates chondrogenesis both in vitro and in vivo. ${ }^{18}{ }^{19}$ CDMP-1 and CDMP-2 stimulated synthesis of aggrecan, the aggregating proteoglycans. The CDMPs preferentially stimulated chondrogenesis. On the other hand, CDMPs were not as active as BMP-7 in the expression of alkaline phosphatase activity of the MC 3T3-E1 osteoblastic cell line and ROB-C26 osteoprogenitor cells. In humans, patients with Hunter-Thompson chondrodysplasia exhibit mutations in the CDMP-1 gene locus. ${ }^{20}$ The recent work of Wolfman and colleagues has demonstrated the potential role of GDF-7 in tendon and ligament morphogenesis. ${ }^{21}$ Thus the CDMPs/GDFs may be critical in joint morphogenesis.

During limb morphogenesis there is an intricate dynamic reciprocal interaction between ectodermally derived apical ectodermal ridge and mesodermally derived mesenchyme. BMP-2 is expressed in the mouse limb bud. ${ }^{22}$ BMP-3 (osteogenin) and BMP-4 stimulate chondrogenesis in vitro through the prechondrogenic mesodermal cells of the chick limb bud. ${ }^{23-27}$ BMP-7 is localised in perichondrium and chondrocytes in the early phases of cartilage morphogenesis in humans. ${ }^{28}$ Human articular chondrocytes express BMP-7. ${ }^{29}$

Other growth factors may play a part in cartilage and limb morphogenesis. Fibroblast growth factor-4 (FGF-4) can mimic the actions of apical ectodermal ridge ${ }^{30} 31$ in the limb bud. In addition, beads soaked in FGF-4 induce formation of ectopic limb buds. ${ }^{32}$ A polarising signal sonic hedgehog and a homoeobox gene Hoxd 13 are induced by FGF-4. The FGF receptors are tyrosine kinases and mediate the action of this class of growth factors. Expression of FGF receptor-3 was maximal in resting cartilage. ${ }^{33}$ Mutations in FGF receptor 3 were identified in an autosomal dominant form of dwarfism achondroplasia. $^{34}{ }^{35}$ Other growth factors regulate cartilage differentiation. ${ }^{36}$ FGFs inhibit the terminal differentiation of chondrocytes. ${ }^{37}$ Insulin-like growth factor, connective tissue growth factor, parathyroid hormone, and other related factors have an important role in chondrocytes..$^{38-42}$

The stability of the phenotype of articular chondrocytes is critically dependent on cell shape and cell density. The geometry of the cell culture is critical for chondrocyte gene expression. ${ }^{43}$ In monolayer cell culture chondrocytes, cartilage phenotype is progressively lost with passage of time. This can be delayed or avoided by high density micromass cultures or pellet cultures. Alternatively, use of explant cultures of articular cartilage permits the chondrocytes to be encased with their own extracellular matrix. Recombinant human BMP-4, activin and TGF $\beta$ can maintain the articular cartilage phenotype. ${ }^{43}{ }^{44}$ Very recently, it was shown that BMP-7 at concentrations of 30 and $100 \mathrm{ng} / \mathrm{ml}$ maintained and stimulated the biosynthesis of sulphated proteoglycans. ${ }^{45}$ The hydrodynamic size and composition of the glycosaminoglycan chains were identical in both the BMP-7 treated subjects and the controls. Thus BMPs may initiate chondrogenesis in vivo and maintain articular cartilage in vitro in chemically defined medium.

CDMP-1 plays a part in the initiation and promotion of mesenchymal cell recruitment and chondrocyte differentiation $^{46}$ CDMP-1 regulates chondroprogenitor cell proliferation and chondrocyte differentiation and hypertro- phy. CDMP-1 and -2 promote the differentiation of bone marrow stromal stem cells into bone cells. ${ }^{47}$ In related studies periosteal cells were stimulated by CDMP-1 and -2 to form both chondrocytes and osteogenic cells. ${ }^{48}$

As CDMPs are critical for cartilage morphogenesis it was of interest to evaluate them in both normal and osteoarthritic articular chondrocytes. CDMPs are expressed in both normal and osteoarthritic cartilage and the chondrocytes derived from both sources are responsive to CDMPs, stimulating proteoglycan biosynthesis. ${ }^{49}$

During progressive osteoarthritis bony outgrowths from the margins of articular cartilage result in osteophyte formation. Osteophytes are considered to be regenerative attempts to repair articular cartilage in osteoarthritis. CDMP-1, -2 , and -3 were expressed in chondrocytes in the osteophytes. ${ }^{50}$ BMP-2 and -3 were localised in osteoblasts, BMP- 6 was found in osteocytes and BMP-7 in both hypertrophic chondrocytes and in osteocytes. ${ }^{50}$

\section{BMP AND CDMP RECEPTORS}

Recombinant human BMP-4 and BMP-7 bind to BMP receptor IA (BMPR-IA) and BMP receptor IB (BMPR-IB). ${ }^{51}$ CDMP-1 also binds to both BMPR-IA and IB. There is collaboration between type I and type II BMP receptors, ${ }^{13}$ and they are both membrane bound serine/threonine kinases. The BMP type II receptors phosphorylate BMP type I receptor. The phosphorylated BMP type I receptor in turn phosphorylates a signal transducing acceptor protein Smad, a term derived from fusion of Drosophila Mad and nematode genes Sma-2, -3, and -4 . There are eight Smads. Phosphorylated Smad -5 and -8 are functional mediators of BMP signalling in partnership with Smad-4 (fig 1). Smad-6 and -7 are inhibitory to phosphorylation of Smad-1 and -5 catalysed by BMP type I receptor. Smad- -2 and -3 are involved in activin and TGF $\beta$ signalling. The transcription of BMP response genes is initiated by the signalling complex of Smad-1 and Smad-4. BMPs and CDMPs may also regulate cell cycle progression. Cytoskeletal compartmentation of signalling complexes such as Smads may regulate the differentiation of chondroprogenitor cells into chondrocytes.

The downstream targets of BMP and CDMPs are most certainly homoeobox genes. In vertebrates there are four clusters of homoeobox genes: $\mathrm{a}, \mathrm{b}, \mathrm{c}$, and $\mathrm{d}^{52}$ There is a temporal collinearity during homoeobox gene expression. ${ }^{53}$ Considerable excitement has been generated about the presence of homoeodomain proteins in chondrocytes. ${ }^{54-56}$ BMPs, in turn, may be regulated by members of the hedgehog family. ${ }^{57} 58$

\section{INTERLEUKIN 17 FAMILY AND CARTILAGE HOMOEOSTASIS}

IL17 is a proinflammatory cytokine secreted by activated T cells. The IL17 family consists of related molecules and are listed alphabetically IL17A, IL17B, IL17C, IL17D, IL17E, and IL17F. IL17B (also known as chondroleukin) was isolated from articular cartilage by purification and protein chemistry. ${ }^{59}$ IL17B is localised immunocytochemically in midzone and deep chondrocytes in articular cartilage. It is a catabolic cytokine in articular chondrocyte explants and in chondrocytes. The anabolic actions of BMP-7 are blocked by IL17A and IL17B (Grayson, Moseley, and Reddi, unpublished data).

As CDMPs and BMPs are critical for cartilage morphogenesis and articular cartilage maintenance they may be considered as anabolic. In osteoarthritis cartilage is degraded by catabolic cytokines ILl, ILl7, and TNF $\alpha$.

The homoeostasis of articular cartilage in the joint is a balance between anabolic morphogens such as BMPs and CDMPs and catabolic cytokines such as ILl, IL17, and TNF $\alpha$. BMPs and CDMPs induce cartilage morphogenesis and maintenance. The BMP antagonists and catabolic cytokines contribute to the feeble innate capacity for regeneration of articular 


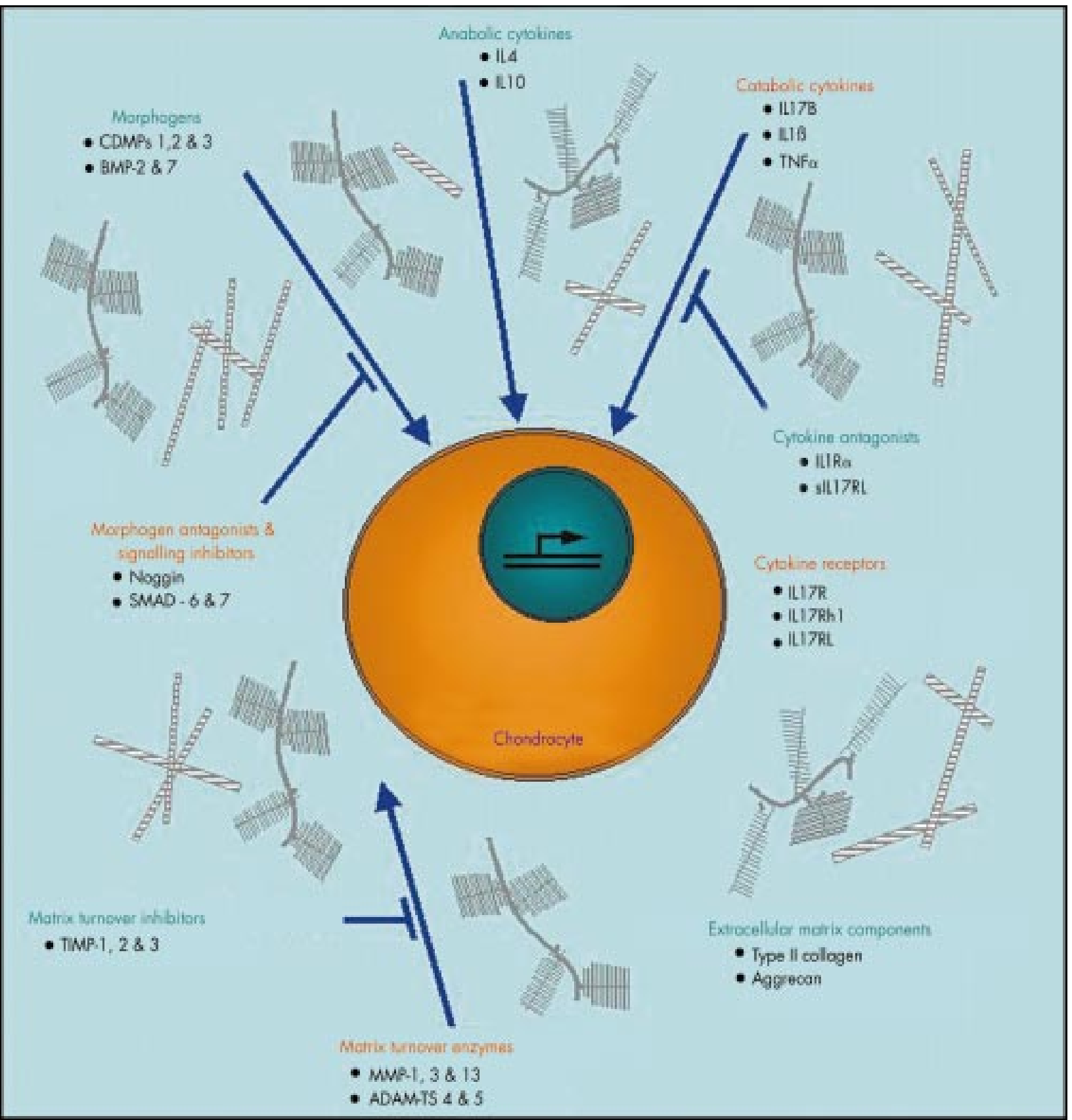

Figure 1 Articular cartilage homoeostasis in the joint. Anabolic morphogens such as CDMPs and BMPs initiate cartilage morphogenesis and maintain the extracellular matrix components such as collagens II, IX, and XI and aggrecan. On the other hand, catabolic cytokines such as the interleukin (IL) 1, IL 17 family, and tumour necrosis factor $\alpha$ (TNF $\alpha$ ) degrade the cartilage matrix by stimulating matrix turnover enzymes and inhibiting the tissue inhibitors of metalloproteinases. The actions of BMPs are antagonised by BMP antagonists, noggin, chordin, and DAN. The structural integrity of the extracellular matrix is vital to cartilage homoeostasis. Alterations in articular cartilage homoeostasis may lead to progressive loss of articular function in arthritis. Advances in targeted therapeutic agents to block aggrecanases and catabolic cytokines may lead to improved cartilage homoeostasis.

cartilage..$^{59}$ Thus, at steady state the articular cartilage homoeostasis is a delicate balance of anabolic morphogens and catabolic cytokines (fig 1).

\section{ASSEMBLY OF EXTRACELLULAR MATRIX}

Morphogenesis of cartilage is intimately linked to the supramolecular assembly of the extracellular matrix. Cartilage matrix is composed of collagens, proteoglycans, and glycoproteins. ${ }^{60}$ The bulk collagen of the cartilage matrix is collagen II with minor collagens IX and XI. Genetic mutations in collagen II result in chondrodysplasias and cartilage degeneration. ${ }^{61-63}$ Overexpression of SV40 large T antigen with regulatory element of COL2Al gene leads to skeletal defects. ${ }^{64}$

Although type IX collagen is a minor component of cartilage matrix, it has a major role as assessed by gene knockout experiments. ${ }^{65}{ }^{66}$ When type IX collagen expression is disrupted by homologous recombination, mice develop osteoarthritis with age. Similarly, mutations in type X collagen result in Schmid metaphyseal chondrodysplasia. ${ }^{67}$ However, in mice, disruption of type X collagen by homologous recombination, skeleton was not affected..$^{68}$ Skeletal morphogenesis is critically dependent on type XI collagen. In an autosomal 
dominant form of Stickler syndrome, exon-skipping was identified in COL11A2 due to a mutation in the splice donor site. $^{69}$

The binding of BMPs to collagens I and IV and heparin raises the possibility that morphogens bind to extracellular matrix. The biological consequence of such a binding includes restriction of the mobility of the morphogen, inhibition and/or termination of the morphogen's action, and the protection of morphogen from non-specific proteolysis.

The antagonism of cartilage and bone morphogenetic protein actions may be mediated by other binding proteins. Noggin is a BMP antagonist secreted by Spemann organiser, which was initially suspected to be an inducer of neural tissues. Thus a specific "inducer" may terminate the action of a dominant morphogen (BMP) and promote a default pathway of neural cell lineage. Recently, when noggin gene was knocked out by homologous recombination, joint morphogenesis was profoundly impaired. ${ }^{3}$ However, it is not clear whether the absence of noggin influenced the longevity and survival of chondrocytes. Additional experiments using conditional mutants generated by the cre-lox system with regulated tissue-specific noggin expression might alleviate the defects in joint morphogenesis in noggin null mice. There was no effect on the homoeobox gene Hoxd and Indian hedgehog expression, which are known to be involved in cartilage morphogenesis.

Because cartilage is damaged in arthritis the current progress in cartilage morphogenetic proteins may aid in regeneration of articular cartilage. After all, regeneration is in part a recapitulation of embryonic development and morphogenesis. In fact, the emerging discipline of tissue engineering seeks to restore function to diseased or damaged tissues based on morphogenetic proteins. ${ }^{2}$ Thus, CDMPs may alleviate the pain of osteoarthritic patients with regeneration of articular cartilage. Regenerative medicine of cartilage is based on the triad of signals, stem cells, and scaffolds. ${ }^{2}$ Recent advances in regenerative medicine bode well for amelioration of pain in patients with arthritis.

\section{Author's affiliation}

A H Reddi, Centre for Tissue Regeneration and Repair, Department of Orthopaedic Surgery, University of California, Davis School of Medicine, Sacramento, California 95817, USA

Correspondence to: Professor A H Reddi, Research Bldg I, Rm 2000, 4635 Second Avenue, Sacramento, CA 95817, USA

ahreddi@ucdavis.edu

\section{REFERENCES}

1 Reddi AH. Cartilage morphogenesis: role of bone and cartilage morphogenetic proteins, homeobox genes and extracellular matrix. Matrix Biol 1995; 14:599-606.

2 Reddi AH. Role of morphogenetic proteins in skeletal tissue engineering and regeneration. Nat Biotechnol 1998;16:247-52

3 Brunet LJ, McMahon JA, McMahon AP, Harland RM. Noggin, cartilage morphogenesis, and joint formation in the mammalian skeleton. Science 1998;280:1455-7.

4 Wilkinson LS, Pitsillides AA, Worrall JG, Edwards JC. Light microscopic characterization of the fibroblast-like synovial intimal cell (synoviocyte). Arthritis Rheum 1992;35:1179-84.

5 Pacifici M, Golden EB, Oshima O, Shapiro IM, Leboy PS, Adams SL. Hypertrophic chondrocytes. The terminal stage of differentiation in the chondrogenic cell lineage? Ann N Y Acad Sci 1990;599:45-57.

6 Reddi AH, Huggins C. Biochemical sequences in the transformation of normal fibroblasts in adolescent rats. Proc Natl Acad Sci USA 1972:69:1601-5

7 Urist MR. Bone: formation by autoinduction. Science 1965;150:893-9.

8 Reddi AH. Cell biology and biochemistry of endochondral bone development. Coll Relat Res 1981;1:209-26.

9 Reddi AH. Extracellular matrix and development. In: Piez KA, Reddi $\mathrm{AH}_{\text {, }}$ eds. Extracellular matrix biochemistry. New York: Elsevier, 1984:375-412.

10 Sampath TK, Reddi AH. Dissociative extraction and reconstitution of extracellular matrix components involved in local bone differentiation. Proc Natl Acad Sci USA 1981;78:7599-603.

11 Reddi AH. Regulation of cartilage and bone differentiation by bone morphogenetic proteins. Curr Opin Cell Biol 1992;4:850-5.
12 Reddi AH. Bone and cartilage differentiation. Curr Opin Genet Dev 1994:4:737-44.

13 Reddi AH. Bone morphogenetic proteins: an unconventional approach to isolation of first mammalian morphogens. Cytokine Growth Factor Rev 1997; 8: 11-20.

14 Zhou X, Sasaki H, Lowe L, Hogan BL, Kuehn MR. Nodal is a novel TGF-beta-like gene expressed in the mouse node during gastrulation. Nature 1993;361:543-7.

15 Cunningham NS, Jenkins NA, Gilbert DJ, Copeland NG, Reddi AH, Lee SJ. Growth/differentiation factor-10: a new member of the transforming growth factor-beta superfamily related to bone morphogenetic protein-3. Growth Factors 1995; 12:99-109.

16 Chang SC, Hoang B, Thomas JT, Vukicevic S, Luyten FP, Ryba NJ, et al. Cartilage-derived morphogenetic proteins. New members of the transforming growth factor-beta superfamily predominantly expressed in long bones during human embryonic development. J Biol Chem 1994:269:28227-34.

17 Storm EE, Huynh TV, Copeland NG, Jenkins NA, Kingsley DM, Lee SJ. Limb alterations in brachypodism mice due to mutations in a new member of the TGF beta-superfamily. Nature 1994;368:639-43.

18 Hotten GC, Matsumoto T, Kimura M, Bechtold RF, Kron R, Ohara T, et al. Recombinant human growth/differentiation factor 5 stimulates mesenchyme aggregation and chondrogenesis responsible for the skeletal development of limbs. Growth Factors 1996; 13:65-74.

19 Erlacher L, McCartney J, Piek E, ten Dijke P, Yanagishita M, Oppermann $\mathrm{H}$, et al. Cartilage-derived morphogenetic proteins and osteogenic protein-1 differentially regulate osteogenesis. J Bone Miner Res 1998; 13:383-92.

20 Thomas JT, Lin K, Nandedkar M, Camargo M, Cervenka J, Luyten FP. A human chondrodysplasia due to a mutation in a TGF-beta superfamily member. Nat Genet 1996;12:315-17

21 Wolfman NM, Hattersley G, Cox K, Celeste AV, Nelson R, Yamaji N, et al. Ectopic induction of tendon and ligament in rats by growth and differentiation factors 5,6 , and 7 , members of the TGF-beta gene family. J Clin Invest 1997; 100:321-30.

22 Lyons KM, Pelton RW, Hogan BL. Organogenesis and pattern formation in the mouse: RNA distribution patterns suggest a role for bone morphogenetic protein-2A (BMP-2A). Development 1990;109:833-44

23 Carrington JL, Chen $\mathrm{P}$, Yanagishita $\mathrm{M}$, Reddi AH. Osteogenin (bone morphogenetic protein-3) stimulates cartilage formation by chick limb bud cells in vitro. Dev Biol 1991;146:406-15.

24 Chen P, Carrington JL, Hammonds RG, Reddi AH. Stimulation of chondrogenesis in limb bud mesoderm cells by recombinant human bone morphogenetic protein 2B (BMP-2B) and modulation by transforming growth factor beta 1 and beta 2. Exp Cell Res 1991;195:509-15.

25 Chen P, Carrington JL, Paralkar VM, Pierce GF, Reddi AH. Chick limb bud mesodermal cell chondrogenesis: inhibition by isoforms of platelet-derived growth factor and reversal by recombinant bone morphogenetic protein. Exp Cell Res 1992;200:110-17.

26 Francis PH, Richardson MK, Brickell PM, Tickle C. Bone morphogenetic proteins and a signalling pathway that controls patterning in the developing chick limb. Development 1994;120:209-18.

27 Kawakami Y, Ishikawa T, Shimabara M, Tanda N, Enomoto-lwamoto $M$, Iwamoto $M$ et al. BMP signaling during bone pattern determination in the developing limb. Development 1996;122:3557-66.

28 Vukicevic S, Latin V, Chen P, Batorsky R, Reddi AH, Sampath TK. Localization of osteogenic protein-1 (bone morphogenetic protein-7) during human embryonic development: high affinity binding to basement membranes. Biochem Biophys Res Commun 1994;198:693-700.

29 Chubinskaya S, Merrihew C, Cs-Szabo G, Mollenhaver J, McCartney J, Rueger DC, et al. Human articular chondrocytes express osteogenic protein-1. J Histochem Cytochem 2000;48:239-50.

30 Niswander L, Tickle C, Vogel A, Booth I, Martin GR. FGF-4 replaces the apical ectodermal ridge and directs outgrowth and patterning of the limb. Cell 1993.75:579-87.

31 Fallon JF, Lopez A, Ros MA, Savage MP, Olwin BB, Simandl BK. FGF-2 apical ectodermal ridge growth signal for chick limb development. Science 1994;264:104-7.

32 Cohn MJ, Izpisua-Belmonte JC, Abud H, Heath JK, Tickle C. Fibroblast growth factors induce additional limb development from the flank of chick embryos. Cell 1995;80:739-46.

33 Peters K, Ornitz D, Werner S, Williams L. Unique expression pattern of the FGF receptor 3 gene during mouse organogenesis. Dev Biol 1993; 155:423-30.

34 Shiang $\mathbf{R}$, Thompson LM, Zhu YZ, Church DM, Fielder TJ, Bocian M, et al. Mutations in the transmembrane domain of FGFR3 cause the most common genetic form of dwarfism, achondroplasia. Cell 1994;78:335-42

35 Rousseau F, Bonaventure J, Legeai-Mallet L, Pelet A, Rozet JM, Maroteaux $\mathrm{P}$, et al. Mutations in the gene encoding fibroblast growth factor receptor-3 in achondroplasia. Nature 1994:371:252-4.

36 Cancedda R, Descalzi Cancedda F, Castagnola P. Chondrocyte differentiation. Int Rev Cytol 1995;159:265-358.

37 Kato Y, Iwamoto M. Fibroblast growth factor is an inhibitor of chondrocyte terminal differentiation. J Biol Chem 1990;265:5903-9.

38 Amizuka N, Warshawsky H, Henderson JE, Goltzman D, Karaplis AC. Parathyroid hormone-related peptide-depleted mice show abnormal epiphyseal cartilage development and altered endochondral bone formation. J Cell Biol 1994;126:1611-23.

39 Karaplis AC, Luz A, Glowacki J, Bronson RT, Tybulewicz VL, Kronenberg $\mathrm{HM}$, et al. Lethal skeletal dysplasia from targeted disruption of the parathyroid hormone-related peptide gene. Genes Dev 1994;8:277-89. 
40 Kawashima-Ohya $Y$, Satakeda $\mathrm{H}$, Kuruta $Y$, Kawamoto $T$, Yan W Akagawa $Y$, et al. Effects of parathyroid hormone (PTH) and PTH-related peptide on expressions of matrix metalloproteinase-2, -3 , and -9 in growth plate chondrocyte cultures. Endocrinology 1998;139:2120-7.

41 Nakanishi T, Kimura Y Tamura T, Ichikawa H, Yamaai $Y$, Sugimoto $T$, et al. Cloning of a mRNA preferentially expressed in chondrocytes by differential display-PCR from a human chondrocytic cell line that is identical with connective tissue growth factor (CTGF) mRNA. Biochem Biophys Res Commun 1997;234:206-10.

42 Takigawa $M$, Okawa T, Pan H, Aoki C, Takahashi K, Zue J, et al. Insulin-like growth factors I and II are autocrine factors in stimulating proteoglycan synthesis, a marker of differentiated chondrocytes, acting through their respective receptors on a clonal human chondrosarcoma-derived chondrocyte cell line, HCS-2/8. Endocrinology 1997:138:4390-400.

43 Luyten FP, Chen P, Paralkar V, Reddi AH. Recombinant bone morphogenetic protein-4, transforming growth factor- beta 1, and activin A enhance the cartilage phenotype of articular chondrocytes in vitro. Exp Cell Res 1994;210:224-9.

44 Luyten FP, Yu YM, Yanagishita M, Vukicevic S, Hammonds RG, Reddi $\mathrm{AH}$. Natural bovine osteogenin and recombinant human bone morphogenetic protein-2B are equipotent in the maintenance of proteoglycans in bovine articular cartilage explant cultures. J Biol Chem 1992;267:3691-5

45 Lietman SA, Yanagishita M, Sampath TK, Reddi AH. Stimulation of proteoglycan synthesis in explants of porcine articular cartilage by recombinant osteogenic protein-1 (bone morphogenetic protein-7). J Bone Joint Surg Am 1997;79:1 132-7

46 Tsumaki N, Tanaka K, Arikawa-Hirasawa E, Nakase T, Kimura T, Thomas JT, et al. Role of CDMP-1 in skeletal morphogenesis: promotion of mesenchymal cell recruitment and chondrocyte differentiation. J Cell Biol 1999; 144:161-73.

47 Gruber R, Mayer C, Schulz W, Graninger W, Peterlik M, Watzek G, et al. Stimulatory effects of cartilage-derived morphogenetic proteins 1 and 2 on osteogenic differentiation of bone marrow stromal cells. Cytokine 2000; 12:1630-8.

48 Gruber R, Mayer C, Bobacz K, Krauth MT, Graninger W, Luyten FP, et al. Effects of cartilage-derived morphogenetic proteins and osteogenic protein-1 on osteochondrogenic differentiation of periosteum-derived cells. Endocrinology 2001;142:2087-94.

49 Bobacz K, Gruber R, Soleiman A, Graninger WB, Luyten FP, Erlacher L. Cartilage-derived morphogenetic protein-1 and -2 are endogenously expressed in healthy and osteoarthritic human articular chondrocytes and stimulate matrix synthesis. Osteoarthritis Cartilage 2002;10:394-401.

50 Zoricic S, Maric I, Bobinac D, Vukicevic S. Expression of bone morphogenetic proteins and cartilage-derived morphogenetic proteins during osteophyte formation in humans. J Anat 2003;202(Pt 3):269-77

51 ten Dijke P, Yamashita H, Sampath TK, Reddi AH, Estevez M, Riddle DL, et al. Identification of type I receptors for osteogenic protein-1 and bone morphogenetic protein-4.J Biol Chem 1994:269:16985-8.

52 Krumlauf R. Hox genes in vertebrate development. Cell 1994;78:191-201.
53 Dolle $\mathbf{P}$, Dierich A, LeMeur M, Schimmang T, Schuhbaur B, Chambon P, et al. Disruption of the Hoxd-13 gene induces localized heterochrony leading to mice with neotenic limbs. Cell 1993;75:431-41.

54 Zhao GQ, Zhou X, Eberspaecher H, Solursh M, de Crombrugghe B. Cartilage homeoprotein 1, a homeoprotein selectively expressed in chondrocytes. Proc Natl Acad Sci USA 1993:90:8633-7.

55 Zhao GQ, Eberspaecher H, Seldin MF, de Crombrugghe B. The gene for the homeodomain-containing protein Cart-1 is expressed in cells that have a chondrogenic potential during embryonic development. Mech Dev 1994;48:245-54

56 Wright E, Hargrave MR, Christiansen J, Cooper L, Kun J, Evans T, et al. The Sry-related gene Sox9 is expressed during chondrogenesis in mouse embryos. Nat Genet 1995;9:15-20.

57 Johnson RL, Tabin C. The long and short of hedgehog signaling. Cell 1995;81:313-16

58 Riddle RD, Johnson RL, Laufer E, Tabin C. Sonic hedgehog mediates the polarizing activity of the ZPA. Cell 1993:75:1401-16.

59 Moseley TA, Haudenschild DR, Rose L, Reddi AH. Interleukin-17 family and IL-17 receptors. Cytokine Growth Factor Rev 2003;14:155-74.

60 Bruckner $\mathbf{P}$, van der Rest $M$. Structure and function of cartilage collagens. Microsc Res Tech 1994;28:378-84.

61 Vikkula M, Metsaranta M, Ala-Kokko L. Type II collagen mutations in rare and common cartilage diseases. Ann Med 1994:26:107-14.

62 Freisinger $\mathbf{P}$, Ala-Kokko L, LeGuellec D, Franc S, Bouvier R, Ritvaniemi $P$, et al. Mutation in the COL2Al gene in a patient with hypochondrogenesis. Expression of mutated COL2Al gene is accompanied by expression of genes for type I procollagen in chondrocytes. J Biol Chem 1994;269:13663-9.

63 Chan D, Cole WG, Chow CW, Mundlos S, Bateman JF. A COL2A mutation in achondrogenesis type II results in the replacement of type II collagen by type I and III collagens in cartilage. J Biol Chem 1995;270:1747-53

64 Cheah KS, Levy A, Trainor PA, Wai AW, Kuffner T, So CL, et al. Human COL2A l-directed SV40 T antigen expression in transgenic and chimeric mice results in abnormal skeletal development. J Cell Biol 1995; 128:223-37

65 Nakata K, Ono K, Miyazaki J, Olsen BR, Muragaki Y, Adachi E, et al. Osteoarthritis associated with mild chondrodysplasia in transgenic mice expressing alpha 1 (IX) collagen chains with a central deletion. Proc Nat Acad Sci USA 1993:90:2870-4.

66 Fassler R, Schnegelsberg PN, Dausman J, Shinya T, Muragaki Y McCarthy MT, et al. Mice lacking alpha 1 (IX) collagen develop noninflammatory degenerative joint disease. Proc Natl Acad Sci USA 1994;91:5070-4.

67 Warman ML, Abbott M, Apte SS, Hefferon T, Mclntosh I, Cohn DH, et al. A type $X$ collagen mutation causes Schmid metaphyseal chondrodysplasia. Nat Genet 1993;5:79-82

68 Rosati R, Horan GS, Pinero GJ, Garofalo S, Keene DR, Horton WA, ef al. Normal long bone growth and development in type $\mathrm{X}$ collagen-null mice. Nat Genet 1994;8:129-35.

69 Vikkula M, Mariman EC, Lui VC, Zhidkova NI, Tiller GE, Goldring MB, et al. Autosomal dominant and recessive osteochondrodysplasias associated with the COL11A2 locus. Cell 1995;80:431-17. 